\title{
PHYSIOTHERAPY IN GERIATRICS IN THE TRANSVAAL
}

\author{
JOHLYNE C. BEENHAKKER, B.Se (Physiotherapy), D.P.E. (Witwatersrand)*
}

Physiotherapy was not considered an integral part of Geriatric Care in South Africa until the end of 1958 when a team of volunteers initiated a rehabilitative programme at one of the homes in Johannesburg.

By the beginning of the following year an attcmpt had been made to promote preventative physiotherapy amongst active elderly residents and classes were given twice weekly in the evenings. This proved to be very successful and soon a Associate Professor and Acting Head of Sub-Department of
Physiotherapy, University of Witwatcrsrand.

Received 15 March 1982. paid. part-time physiotherapist was appointed at the home to carry out curative treatment whilc the volunteers continued with their evening sessions.

In 1961 the tean was approached by the Rand Aid Association to extend their services to other homes in Johannesburg and with the backing of the S.A. Society of Physiotherapy, three further homes were included in the programme.

The value of the work done by thesc early pioneers in this field was gradually recognised and by the end of 1964 several homes had appointed part-time physiotherapists to their staff. 
At the biennial meeting of the S.A. Council for the Care of the Aged held in Port Elizabeth in 1965, the first multidisciplinary symposium was organised to discuss the role of the various health workers. $\mathrm{Mr}$ A. Rothberg, who represcnted the S.A.S.P., discussed the importance of physiotherapy and the part it played in the general team approach.

This symposium stirred the interest of Natal and the Western Cape and gradually their services for the elderly overtook those of the Transvaal. Physiotherapy students from the Cape and Pretoria were also encouraged to run fitness classes for residents at homes in their areas.

Although the need for open-air sports and recreation clubs for senior citizens was realised, no able-bodied sports club could be persuaded to allow the elderly non-members to use their facilities. However, in 1972 the Mandeville Sport and Social Centre opened its doors and in co-operation with the Johannesburg Council for the Care of the Aged and Rotary Johannesburg South, the Mandeville Senior Citizens Club was developed.

The sport and recreation club under the guidance of $\mathrm{Mr}$ Rothberg has proved most successful with its outdoor games and indoor recreational activities, which include fitness classes. It has also been the prototype for others in Johannesburg, Edenvale, Benoni. Krugersdorp, Springs and Soweto.

In 1974 the S. A. Society of Physiotherapy was asked by the Witwatersrand Technikon to draw up a lecture course on physiotherapy in the care of the aged. This is one of the subjects offered for the National Certificate of Institutional Care for aides in Homes for the Aged. Mr Rothberg compiled the syllabus and has been an examiner in this subject until the present time.

It was realised that undergraduate students should be made aware of the need to treat geriatric patients in the community and in 1978 the students of the University of Witwatersrand were given this experience. Three homes close to the Medical School which had never had the services of physiotherapists, were chosen. At these homes the handling of residents generally promoted a dependent attitude.

By $198 \mathrm{I}$ most of the teething problems experienced at these homes had been sorted out and the staff are most enthusiastic about physiotherapy. They have come to realise the importance of fitness classes and correct handling of patients in the overall programme of residents.

During the same period three service centres were visited and weekly fitness classes were olfered to the members, Three new centres were opened in 1982 and the need for physiotherapy has been given high priority.

The Municipal Senior Citizens" recreation clubs in Johannesburg are looking for helpers to arrange fitness classes in Jabula, Braamfontein and Yeoville. Social workers at Senior Citizens' Clubs in Soweto have already instituted classes in various areas.

The demand for physiotherapy in the Care of the Aged is increasing and means for catering for this need will have to be found. Physiotherapists throughout the Republic are being invited to investigate what the needs in their own areas are and to suggest how these may be met. Relatively few homes have a regular physiotherapist in attendance while the need in rural areas, away from the larger centres, is known to be even more acute. 